\title{
MULTI COMPONENT COMPOSITE SENTENCES MADE ON THE BASE OF THE CONCENTRIC-COMMON SUBORDINATIONS
}

\author{
Kemale AHMEDOVA \\ Associate Professor Of Turkish Philology Faculty Of Oriental Studies \\ Baku State University \\ Azerbaijan Republic, Baku city Zahid Khalilov str.-23 AZ1148
}

\begin{abstract}
In Turkic, in particular, in the Azerbaijan linguistics hitherto polynomial mixed complex sentences were not the subject of a special monographic study. This work deals with the problem of mixed complex sentences in the Azerbaijan language, revealing a variety of structural and semantic models and their variants on the basis of logical and syntactical and structural level division, the definition of the place or the other component in the overall structure of the multi-mixed complex sentence. For the first time an attempt is made to identify the components (structural units) with different semantic relations at different levels of the polynomial division and to present a mixed complex sentence as communicative syntactic whole. Studies show that such multi component composite sentences very compact, i.e. components at any level of division are interrelated and interdependent. Polynomial mixed complex sentences of this type in the modern Azerbaijan occur very rarely. They are very bulky in terms of the number of predicative units, and in terms of components representing a particular sentence structure, although such multi component composite sentences easy on perception. Choosing a theme is not only due to the lack of material of modern Azerbaijan any research, as well as the need to determine the grammatical nature, the compatibility of components, representing not only simple but also complex and sophisticated components.
\end{abstract}

Keywords: Azerbaijan language, litreture, linguistics

\section{INTRODUCTION}

Two groups of multi component composite sentences that we will be looked through in the following has been the investigation object in our linguistics and took place in many textbooks as programs materials at the high institutions. If the Russian linguistics polynomial complex sentences were the subject of a separate study, the Tatar language similar designs were mentioned only in school and general college textbooks. According to the academician M.Z.Zakieva "The theme of the polynomial complex sentences already allocated to study (not a grammatical relationship between sentences) structure of such highly complex structures (Zakiyev, 1995: 519). A review of the scientific literature, the least studied and structurally and in terms of semantic relations between the components are polynomials mixed complex sentence.

The type of multi component composite sentences that made on the base of concentric-common (then "concentric") subordinations we think and hope that will be find its first researches in Azerbaijan linguistics in the presented scientific work.

It is known that when the researchers give examples to some types of complex sentences and the MCCS they attract according sentences viewpoint of structure to the analyses. The same situation became as an ordinary habit. Both in Russian linguistics and in Turkish linguistics we see the same situations. As illustrative materials it is very important to differentiate the attracted constructions, but just consider these sentences as adequade-identic on the base of the structural synonymous do not justify themselves. 
In Russian linguistics these constructions have the investigation objects and as special constructive model found its description in general system of multi components subordinated complex sentences ${ }^{1}$. It is true that A.M.Peshkoviskiy has never used from "MCCS" conception, being faitful to the traditions of Russian linguistics used "compound" and term. An author on the base of "dependence system" separated the subordinate MCCS into two part - systematic subordination ("the continuous subordinations logically depends on each other's") and collateral subordination. And noted two types of the last - parallel and non - parallel constructions (Peshkovskiy, 1956).

The same differentiation by A.M. Peshkovskiy have found its place both in Russian linguistics and in general Turkology (see according works of E.Z.Abdullayev, I.A.Aziarov, A.Abdurrahmanov, Q.Q.Saitbattalov) and continues to work with those and other correctives. The systematically criterions arranges the foundation of this classification (we can its foundation, vital power and optimality has not lost yet). But in English: Only independent clauses joined by one of the above coordinators are composite sentences. When an independent clause and a dependent clause are joined, a complex sentence is formed, which is distinct from a compound sentence.

When I visit my mother, I eat cookies.

This is not a compound sentence because "When I visit my mother" is not an independent clause and a coordinator is not used.

I like to fish because fishing is fun.

Although "I like to fish" is an independent clause and "fishing is fun" is an independent clause, this is still not a compound sentence. It is a complex sentence, since none of the seven coordinators are used here.

It is true that in the noted research works the structural-semantic type of multicomponent composite sentences calls as fomed sentences on the base of "complex subordination". We deviate from adoption of this term-conception, because, when we say "complex subordination" it is unknown wheater we talk about the complex of subordinate clause or the complex of main clause. In another way, there is also the terminology conception of "the complex relations" that means the comparison of simple sentence to the complex of uncomposite sentences or means the realtions of complex of complex sentences in the structure of composite sentences capacious of multi component composite sentences. In the scientific reasearch work not only multi component composite sentences in the background of "complex relations", " the comparison of complex elements" also the system of compound and asyndetic multi component composite sentences has analized. The presented dissertation work comparatively (on the base of materials of Russian and Azerbaijan linguistics) in the liguistic background has complicated all types of sentences` forms and became to scientific research work. According to our opinion, the conception of "complex relations" has realizes itself in the background of such frontal materials.

\section{METHODOLOGY}

Along the history, the systematic investigation of MCCS in according level, of course has started from the famous work by A.M.Peshkoviskiy. An author, in spite of could not reasoning of systematic confrontation of syntactic realtions (the work was published in 1914), such syntactic realtion in simple and composite sentences gives basic characteristics of opposition: it reasoning the convention of isomorph character of both for composite sentences and for word combinations of subordination and compound relationship (in the structure of simple sentence), also always stresses not join to the coordinating conjunctions in the structure of sentence and as a differential sign of joint usage of subordination means with this or other components (Abdullayev, 1998).

The "generalization levels" of sentence meanings' conventions with carrying out two main functions of the sentence that considers the units of language and speech. One of these functions is the communication unit and another one is the means of formation of thought and idea (Kalashnikova,

\footnotetext{
${ }^{1}$ L.S.Chechulina, Task types on the theme of "MULTI COMPONENT Complex Sentences", At the lesson,
} Moscow? 1971 
1983). The functional load of the first sentence determines with its description-informatic and communicative orientation. Its communicative inclination, participating as the speech and intercourse means determines the syntagmatic independence of this sentence.

But to say the same thoughts about the second and the third sentences are very hard. The sematic structure of paramialogic units measures with its participation as the "existing form of thought andidea" (V.Admoni), as the nomination of intellectual and universal fragment of exralinguistic life's sphere (Hasannova, 1986). So that, to value the syntactic and sematic structuresof aforistic essense or proverbs with the simple speech units point of the same view is not right for theoretical side. Unseparation of paramiya - aforistic constructions, its syntactic close (not depending on their components` numbers) requires them to participate view point of private syntactic structure. On the same sentence is explained the "frazeologicaled" structure that scraped in the human's memory.

For visually presentation lets hold on a little lingustic experience. Lets take out of any of elements of a sentence (word-combination or predicative components). In this moment, there will not be any "linguacreative" processes in tangue-speech memory of the readers. Its reason is that, there is not any stability in lingustic- speech memory of MCCS and such words as "for a long time...", "gang of robbers", "moustached and bearded men..." and etc elements cannot carry the meaning load of construction or the general structure in seperately, the general construction just realize the whole description or informatic effects.

Principally, the functions show that both in ICS and MCCS of the conjuction means are identic. We can say, this classification is developed in all textbooks or monographs that were written on syntactic of Azerbaijan language and determines two formed types on the base of paralel subordinations and continious subordinations of multi components (as "many branched" in A.Abdullayev's terminology) complex sentences.

In this case, we consider the consentric subordination conseption more exact and compehensive that could be take a systematic position with the continious and paralel subordinated conseptions, especially, could characterize its syntactic relations with subordinate clause and main clause.

The predmet of our speech are the following structural forms of multi component complex sentences: 1) - I want to say that however he comes earlier, we will go out earlier too (Y.Valiyev. "Clouse friends").

2) - Let me die, you got crazy or the death is seeking us...(N.B.Vazirov. "Unfortune Fakhraddin". II majlis).

3) - My grandfather said that if blood passed a night it means, its evidence will be stayed to another world ( B.Bayramov. "Unwritten book". I story).

4) - Even tarist Vali thought, if there was not any sounds of that tar then in the banks of aryk Buzbulagh did not be grow such many mints or violets ( A. Mammadkhani. Tarist).

5) - He gave such information to the people that if anybody say the real place of tiger that person will become into a horse ( F. Karimzadeh. The Chaldiran Fight. VII chapter).

6) - If I listened to you and did not go, then I should be abduct you or you would be still live with your parents. ( M. F. Akhundov. Haji Gara).

7 ) - ... What is the reason, when you are with Mirza, you become into generous but when you come to us why you become into dreedy? (A. Haghverdiyev. The collapsed dwelling house. I majlis).

8) - Gunduz felt and knew that how can say, it will be continue for a long time and this fight will take a long time (S.Rahimov. The mother`s memory. II part. V chapter).

From the "primary" structure of constructions we can see that it is not basically to look them through the frame of paralel or continious subordination and to characterize them inside of this group. The sentence having such spesial forms and essence, assuming such well group in the system of subordinated multi components composite sentences and putting them in front of multi components composite sentences that is made on the base of according parameters complexes or continious subordinations, we can explain all of these with the following factors. 
The second, principal sentence has not any direct relations with any components or this relation is enough weak. And it shows itself as in principal clause any (A component) cannot make concrete syntactic relations with any of components of subordinate clause (one of components of $a$ or $b$ ): the same effort makes such meaning that is inequal to the communicative-semantic structure of artificial and base construction. In most cases, such combination is just impossible.

Because, the components of subordinate clause are under the strong mutual intellectual-essence relations between themselves and explains the principal clause exactly in the same mutual opposite and unit background. Lets have a look through the above mentioned examples:

1. I want to say that however if comes early, how earlier we will go out - this construction "I want to say that" could not make any normative subordinated sentence view point of form and meaning on the base of combination with any components of principal clause of subordinate clause : I want to say that however if comes early (?): I want to say that how earlier we will go out (?).

Such case shows itself in all examples.

The fist reason is that the part of (a-b) subordinate clause is composite sentence with two components, and it consists of such construction that in comporision we just cannot say it is subordinated composite sentence. Exactly the same sentences A.M. Peshkoviski in his time named as "mutual subordinated" that made on the base of subordinated composite sentence and noted that in this case, it is very impossible to determine what component is more depends on another one and what is more under the subordination. A. M. Peshkoviski named such relations types as - out of subordination and coordination frames [Peshkoviskiy, 1965]. But A. M. Peshkoviski as the special type of dual conjunction named them as both two parts of important conjuction.

Thus, one of important sides of consentric subordinations is that the subordinate clause is formalized by conjunction words and by the daul conjunctions: as much as; where ... as there as; who is as...as; everybody as...as; or as...as; if as...as;

In many cases the dual conjunctions ( in the variant of paralel-symmetric double sided composite sentence) is supportid by the special intonation expressing the mutual subordination connection and even it substitude each other. When you see Mirza you become generous, when you reach to us you become greedy.

The third, one of the main peculiarities of multi components composite sentences that formed on the base of consentric subordinations - is the creation of contact line of two subordination conjunctions in the sphere of syntactic connections between; sometimes this line is arranged the first part of dual conjunctions ( or conjunction word) of " that" conjunction coming next; that, if...; where ... that, however... that; how much ...as; or...becouse; how...; because ..if; although...; and etc.

Most researchers that divided the multi components composite sentences as special group of consentric subordination cases, we can say, they see this specific factor (contact line of conjunction means) as constructive (decisive) signs in the opposition that created with other subordinated multi components composite sentences on the base of continious parallel subordination and subordination of the same constructions [Kalashnikova, 1983].

Exactly, this factor gives us the reason to consider non-correct the construction of " president Kvame... said that as much western countries approach to the problems as fanatic, as much they do not give final decisions.., there is immposible to gain progress for getting powerful peace in all over the world "in the plane of paralel subordination and in generally, we should not adopt urgently the determination of structural subordination on the base of continious subordination.

For our opinion, the main reason of being qualification viewpoint of continious subordination of the same constructions, thus, the components that named as prepositive subordinate clause ( for example, beginning with the component of that - conjunction or as mush (long) as - relative conjunctions) sometimes can use after principal clause and in this case, we see the fact of continious subordination: 
-Jahan khanum thought that the number of sheeps is almost more than hundred thousands, if these flock of sheeps were under the control of clever farmer. For comparison: Jahan khanum thought that if these flock of sheeps were under the control of clever farmer then the number of sheeps is almost more than hundred thousands a long time ago (M. Ibrahimov. Parvana, I part, III chapter).

Conditional - cause conditional subordinate clause comes after principal clause, it means, to use "the number of sheeps were more than hundred thousands" before components viewpoint of logical language or dialectic relations is more optimal and logical, so the conditional - cause conditional subordinate clause uses before and in prepositions. Thus, on the base of existence of transformation cases to look through in the frame of continious subordinations of general constructions is not real: in this case, first of all, the preposition rights of conditinal and cause of subordinate clause have to pass ahead, also we should not put the determination of the result with the condition and cause without any attention. It means, to use of cause and conditional subordinate clause is characteric for Azerbaijan, their postposition style arranges variation position. For supporting our opinion it is enough to note that here has not used the language of proverbs, sayings and bayatis in the position of postpositive subordinate clause or they are in rare exceptions. For compare: The long way would be shorter, if your friend is the best=if your friend is the best your way would be shorter (proverb).

There is no doubt that the first form is very correct viewpoint of grammar, but in paremiology collections are used exactly the second form. All of these conditions with being more perfect and conveniency viewpoint of grammar and poetry of the second construction. Compare: if my neighbor would be good my daughter would be married (proverb).

It means, the of subordinate clause and in generally, an order of component structure of these constructions of multi components composite sentences created on the base of concentric subordination basis in itself is syntactically stable and it conveys the constructive base of syntactic units of this stability.

Another forth side that differencies their parallel and continious structures is the potential of beforehand clarifying of the structure of subordinate clause and the semantic capacity of principal clause. The semantic power of principal clause determines (capacity, the semantic load) and "demands" the exact composite structure of subordinate clause; among the noted examples lets look through the fifth sample.

He gave such information to the people that if anybody say the real place of tiger that person will become into a horse.

The world of "information" that used in principal clause, accordingly participates as situative "customer" and determines the conditional -cause meaning relations; the "king information" is realized as the effect and cause also the condition - cause planes (the context of the work demands that): Mahrukh khanum has stayed (with her single son Janali) in Baku for a month. When she went back she gave an ultimatum "but won'tyou marry, then do not wait me here, in Baku again" (S.Rustamkhanli. The beat of heart).

The main side of presented positions is the expression of stable structures of concentric construction of syntactic - paremilogy, in this case, the consideration of simple composite sentence of subordinate clause and in generally, it would not be right if we valued these components viewpoint of quantity position or which of them is the main or which of them depends on another one:

1. My darling knows very well, if he says Sakina to die she will die, if he says stay she will stay (M. Ibrahimov. Parvana, I part, IV chapter).

2. How good our father's said, if anybody cannot find their equal their life will with full of sadness (S. Rahimov. Mother's memory. VIII chapter)

In the showed constructions the representation of subordinate clauses with the stable paremiology units proves that the principal clause components (A), the paramiology structure of principal sentence 
(a,b) clarifies only with concentric meaning, none of parts of subordinate clause complex has not any prioritet in the clarification of meaning structure of prinsipal clause: both of components of stable paremiology units just explain the principal clauses (My darling knows that, ...; How good our fathers said that...) in the mutual units.

However, the determination of specification of concentric structures, clarifying main differencies from the created constructions in the base of parallel subordination or continious subordination of these structures, fist of all, it depends on the interaction between the components of the concentric structures of subordinate clause subordinating itself to be in a logical connection in order to be confirmed. After a component of "how good our fathers said that" can come the "There would not be any combustible if there were not any fire and smoke" in the sentence is a simple sentence with respect to the extent which model is intact, explaining the meaning of the phrase as "Shepherd (if at all) would want he could make cheese from the milk of billy goat", this word is whole, "What do you say?" or "How you said?" are the answers to the whole question.

That is why, in the most cases, continuously or in parallel subordination structures, can be organized "minimal complex sentence" - it is possible to abridge one of three components:

1. I had such conviction that the composer sees me more than anyone else and looking for me more that to anybody (B.Bayramov. Unwritten book. $2^{\text {nd }}$ stories).

2. God knows that how I tried a lot when I was a bricklayer, I worked day and night with my soul, because I have not any other remedy for earning much money for my livings. (M. Huseyn. Morning. Worried city).

The last components in these two constructions of parallel (1) and continious (2) structures - with the saving the functional purpose of other sentence structure - it is not difficult to abridge them. In none of copies of concentric structure there is not any possibilities in this kind of transformations, because the $2^{\text {nd }}$ and $3^{\text {rd }}$ components- $(\mathrm{a} b)$ models between themselves have got such a position that there is not any place to abridge. In other words, principle clause (and its presentedside) can find the functional power only with the components units and realizes on the base of semantic structure that created from the mutual units of components.

The creation of emphatic antithesis components of subordinate clause determines the maintenance of realitions of principal clause. And exactly for this reasonthe dual subordinate clause conjunction and conjunction words means are as in the mold and framed.

In this case, companion part of sentence (or parts) abolishes the order of contact line of conjunction means and is used between them, strengthens the relationship between the syntactic pole of the subordinate clause in the sentence:

1. I know that if you were in the open fight entrenched, you would be probably, gained the famous heroic title. (M. Huseyn. Morning. Worried city).

2. There should not be any eagle in the sky of Caucasus or they hould not rise up to the tops of Caucasus Mountains (S.Rahimov. "Caucasus eagle". Chapter 34).

3. Even at the first day I realized that behind the group of robbers there should be great man for entering to Hashimli`s house or should be very stupid (B.Bayramov. Angel of death).

In the first example of "common element" the role of both pole components of subordinate clause fulfills the promise you: if you were...; You ... could gained a name. In general, such structure is constructed as...

I know that you - if you were ... in an open entrenched

probably gained a name...

In the second sentence as it mentioned elements is adverbial ("Caucasian"), the third sentence is object ("this group of robbers").

\section{DISCUSSION}

It should be noted that the essences of common functional elements components and their interactions contamination of the pole of subordinate clause, should be understand not as the cause of penetrating each other but should be understand as the result. The reason is that as we mentioned above is the 
framed (actual articulation plane) strengthening of dual-parallel subordinate clause means of contamination process of symmetric- parallel components. And it is not necessary as a part of the sentence ensures a common function, in the same sentence can be use two or three parts of sentence, it means in outside of created frame by s can be used a few sentences too.

In these kind of sentences, in many times, in stead of can able to benefit from the subordination relations they can also have higher overall effect in generalization of its identity, subordinating / coordinating syntactic relations from the system. Asydetic relationship and in its background the wide range of functional - meaning of complex and multi-component composite sentences, higher level of abstraction to make a meaningful contribution to their semantic structures as we mentioned in the last chapter, large and small, all genres (especially paremiologic units, Bayati, national words) sufficiently can affirm them.

So let's look at the facts. In frontal look, in proverbs of hundred composite - multicomponent structures you can see only one or two units of "that" conjunction, 7-8 times "if" particles, also 3 and 4 times "but" conjunctions. But in Bayati constructions this ratio is lower, conveys just 2-3\% on the base of "if" conjunctions.

Not going to the deepness of these statistic investigations, such status of multi component composite sentences (in real, MMS) created in this case would not concretely be right to put under doubt of language-linguistic realities and wide polyfunctionality of this relation types.

Such a result, in our opinion, as well as oral speech, but also suitable enough for the sphere of literary language, descriptive language supported by the facts: (...Buy anyway, he must taste this bane). Took his cigarette that he seperated took up smoking, stood up, hesitated, tried to close the door, stopped, turned the key in the door quickly put it away, has stood up and burnt a cigarette for two and three times. (A.Abulhasan. Shy. Sixth chapter).

This kind of description is the product of a purely literary language component asyndetic relation multi component composite sentences between the meaning relations is not suitable to be homogeneous cause of construction means; but in this case, just in one place there is possible to use "and" conjunction, but under this condition it is very impossible to determine the place of conjunction that makes impossible the polarization events oir it is just impossible.

The intonation sphere of this construction (homogeneous intonation structure) between the components would be make fuzzy viewpoint of "poetic aesthetics and stylistics" of the utilization of the sentences with the conjunction means.

In multi component composite sentences the boundaries of poles determines under the condition of meaning relations.

\section{CONCLUSION}

If all of components become to the parallelism - symmetry system then the boundaries of poles realizes in the meaning farme of antonym-opposition, comparison-synonym. And in this case, the phenomenon of asyntetic syntactic relations in this sense announces itself and as its speciality in the word conjunctions proves itself in the plane of composite and multicomponent sentences too.

Here another point is also attracts the attention. Formalized under the condition of asyndetic relations multi component composite sentences being more active in the system of phraseological, syntacticstylistic figures "framed" rhetorical constructions and their communicative / constructive syntax planar sector is the most dynamic and effective organizations and emphasize themself once again; for this cases, in the multi component composite sentences the forms of structures of components sometimes for activity of some "figures" creates very special conditions (5).

At present time, we directed our opinion to the context of question and as much as in our possibilities in in the background of analysis of the language materials. And at the same tijme, the scientific theory 
of the phenomenon, the last word on our sayings about phenomenon is not still seriously enough for admition in the theory.

\section{REFERENCES}

ABDULLAYEV K.M. (1998). The theoretic problems of syntactic of Azerbaijan language. Baku: Maarif,, 150p.

ZAKIEV, M.Z.. (1995). Tatars: problems of history and language: Acad. Sciences Rep. Tatarstan. Dep - of humanitarian. Sciences. - Kazan,. -464p.

PESHKOVSKIY A.M. Russkiy sintaksis v nauchnom osveshchenii. Izd. 7-I. M.: Uchpedgiz, 1956, $511 \mathrm{~s}$.

KALASHNIKOVA G.F.(1983). Sintaksicheskiy status polipredikativnykh slozhnykh predlozheniy i ikh otlichiye ot elementarnykh slozhnykh predlozheniy // Slozhnyye elementarnyye i polipredikativnyye predlozheniya. KALININ: IZD. KGU, S.80.

HASANOVA E.C. (1986). The polypredicativity of composite sentences. Baku, the publishing house of Azerbaijan State University., 83p.

KAZIMOV G.Sh. The modern Azerbaijan language. Syntacsis (the second edition). Baku, 2004,494 p. KAZMIN V.V. (1978). Slozhnyye predlozheniya s sopodchineniyem v sovremennom russkom yazyke / V.V. Kazmin. - (uchebn. Posobiye). - Krasnodar,

KALASHNIKOVA G.F. (1979). Mnogokomponentnyye slozhnyye predlozheniya v sovremennom russkom yazyke / G.F. Kalashnikova. - Khar`kov: Vysshaya shkola,.

KALASHNIKOVA G.F. (1998). Sintaksis mnogokomponentnogo slozhnogo predlozheniyav sisteme filologicheskogo obrazovaniya v vuze i v shkole / G.F. Kalashnikova. - Khar kov: KHGPI,.

RUDAYA N.V.. (2013). Mnogokomponentnyye slozhnyye predlozheniya v sovremennom kitayskom yazyke ( $\mathrm{k}$ postanovke problemy) lınGvistichnı doslidzhennya: $\mathrm{Zb}$. nauk. Pprats' KhnPuim. G.s.skorovodi. - vip. 3535

FRIES, U. (2011). Sentence Length, Sentence Complexity, and the Noun Phrase in 18th-Century News Publications. P.21. Retrieved December 15, 